\title{
STUDI KOORDINASI PERALATAN PROTEKSI OCR DAN GFR PADA PENYULANG TIBUBENENG
}

\author{
Indra Baskara ${ }^{1}$, I W. Sukerayasa ${ }^{2}$, W.G. Ariastina ${ }^{3}$
}

\begin{abstract}
Tibubeneng feeder equipped with protective devices over current relay (OCR) and ground fault relay (GFR) installed in Recloser Dama, Recloser Tandeg and relay feeder Tibubeneng in GI. Based on data from PLN Bali, there are 3 times the interference with the feeder Tibubeneng coordination errors that cause system errors proteksinya.Permasalahan protection coordination can be addressed by the study coordinated analysis of protection systems. The analysis was performed by making a curve existing coordination OCR settings and GFR in Tibubeneng feeders and comparing it with the coordination curve setting calculation results. The calculation is performed based on the standards system of protection of sensitive, reliable, fast and remain selective. Based on the analysis of the existing curve setting, an error occurred coordination between the curve and the GFR Recloser Recloser Tandeg Dama indicated by the curves that intersect at several levels of short circuit current value and the value of grading time OCR and GFR was less than 0.4 seconds. Repair work coordination OCR and GFR in Tibubeneng feeder can be done by re-setting in accordance with the results of calculations in order to obtain protection system in accordance with the terms of the security system.
\end{abstract}

Intisari - Penyulang Tibubeneng dilengkapi peralatan proteksi over current relay (OCR) dan ground fault relay (GFR) yang terpasang di recloser Dama, recloser Tandeg dan relay penyulang Tibubeneng di GI. Berdasarkan data PLN Distribusi Bali, terdapat 3 kali gangguan pada penyulang Tibubeneng yang menyebabkan terjadinya kesalahan koordinasi sistem proteksinya.Permasalahan kesalahan koordinasi proteksi dapat diatasi dengan studi analisis koordinasi sistem proteksi. Analisis dilakukan dengan cara membuat kurva koordinasi setting existing OCR dan GFR pada penyulang Tibubeneng dan membandingkannya dengan kurva koordinasi setting hasil perhitungan.

Kata kunci: Over Current Relay, Ground Fault Relay, Koordinasi Proteksi

\footnotetext{
1 Mahasiswa,Teknik Elektro dan Komputer Universitas Udayana, Kampus Sudirman, Denpasar Bali. Tel. 0361239599, fax: 0361239599; e-mail: indrabaskara @gmail.com

${ }^{2}$ Dosen Teknik Elektro dan Komputer, Universitas Udayana, Kampus Bukit Jimbaran, Badung, Bali, E-mail: sukerayasa@unud.ac.id

${ }^{3}$ Dosen Magister Teknik Elektro dan Komputer Universitas Udayana, Kampus Sudirman, Denpasar Bali. Tel. 0361239599, fax: 0361239599,e-mail: debronxs@yahoo.co.id
}

Perhitungan dilakukan dengan berdasarkan pada standarstandar sistem proteksi yang sensitif, andal, cepat dan tetap selektif. Berdasarkan hasil analisis kurva setting existing, terjadi kesalahan koordinasi antara kurva GFR recloser Dama dan recloser Tandeg yang ditunjukkan dengan adanya garis kurva yang bersinggungan pada beberapa tingkatan nilai arus hubung singkat serta nilai grading time OCR dan GFR yang masih lebih kecil dari 0,4 detik. Perbaikan koordinasi kerja OCR dan GFR pada penyulang Tibubeneng dapat dilakukan dengan melakukan setting ulang sesuai dengan hasil perhitungan agar diperoleh sistem proteksi yang sesuai dengan syarat-syarat sistem pengaman.

\section{PENDAHULUAN}

Penyulang Tibubeneng merupakan jaringan distribusi 20 $\mathrm{kV}$ dengan konfigurasi radial yang terbagi menjadi 3 zona proteksi. Sistem proteksi penyulang dilengkapi dengan dua buah recloser yaitu recloser Tandeg sebagai pengaman zona 3 dan recloser Dama sebagai pengaman zona 2 serta satu buah relay penyulang di gardu induk sebagai pengaman zona 1 yang dilengkapi dengan fungsi over current relay (OCR) dan ground fault relay (GFR).

Berdasarkan data dari PT PLN(Persero) Distribusi Bali, selama kurun waktu tahun 2014 telah terjadi 3 kali gangguan hubung singkat yang menunjukkan indikasi terjadinya kesalahan pada koordinasi sistem proteksi hubung singkat. Penelitian terhadap adanya kesalahan koordinasi sistem proteksi pada penyulang Tibubeneng perlu dilakukan untuk memperbaiki sistem pengamannya agar bekerja sesuai dengan harapan.Kesalahan koordinasi kerja sistem proteksi dapat diketahui melalui proses analisis kurva melalui bantuan program ETAP. Perbaikan sistem pengaman penyulang Tibubeneng dapat diperoleh dengan cara menghitung setting sesuai dengan standar-standar sistem proteksi yang cepat, andal, sensitif dan selektif.

\section{GANGGUAN HUBUNG SINGKAT}

Gangguan hubung singkat adalah gangguan yang terjadi karena adanya kesalahan antara bagian-bagian yang bertegangan.Gangguan hubung singkat dapat menimbulkan arus yang jauh lebih besar dari pada arus normal dan dapat menimbulkan kerusakan peralatan jaringan dan mengganggu batas-batas kestabilan sistem daya[1].Tujuan dari analisis gangguan hubung singkat adalah untuk mengetahui nilai arus hubung singkat yang mungkin terjadi di setiap titk jaringan. Perhitungan arus hubung singkat dapat dihitung dengan mempergunakan persamaan-persamaan berikut [3]: 


$$
\begin{aligned}
& M V A_{s c}=\sqrt{3} \times I_{h s} \times V_{\text {primer }} \\
& Z_{S 2}=\frac{E_{T M}^{2}(k V)}{M V A_{S C}} \\
& X_{T 1}=\% X_{T} x \frac{E_{T M}{ }^{2}}{M V A_{T R}} \\
& X_{T 0}=3 \quad x \quad X_{T 1} \\
& Z_{1 e q}=Z_{S 2}+Z_{1 T R}+Z_{1 j a r} \\
& Z_{0 e q}=Z_{T 0}+3 R N+Z_{0 j a r} \\
& \text { If } 3 \text { fasa }=\frac{E_{p h}}{Z_{1 e q}} \\
& I_{f 2 \text { fasa }}=\frac{E_{p h-p h}}{Z_{1 e q}+Z_{2 e q}} \\
& I_{f 1 \text { fasa }}=\frac{3 \times E_{p h}}{Z_{1 e q}+Z_{2 e q}+Z_{0 e q}}
\end{aligned}
$$

\section{Keterangan:}

MVA $_{\text {SC }}=$ Daya Hubung Singkat Sisi Sumber $150 \mathrm{kV}$ (MVA)

$\mathrm{MVA}_{\mathrm{TR}}=$ Daya Transformator GI (MVA)

$\mathrm{I}_{\mathrm{hs}} \quad=$ Arus Hubung Singkat 3 fasa Sisi $150 \mathrm{kV}(\mathrm{kA})$

$\mathrm{V}_{\text {primer }}=$ Tegangan Sisi Primer $(\mathrm{kV})$

$\mathrm{Z}_{\mathrm{S} 2} \quad=$ Impedansi Sumber Sisi Sekunder (Ohm)

$\mathrm{E}_{\mathrm{TM}} \quad=$ Tegangan Sekunder Transformator GI $(\mathrm{kV})$

$\% \mathrm{X}_{\mathrm{T}} \quad=$ Reaktansi Transformator GI $(\%)$

$\mathrm{X}_{\mathrm{T} 1}=$ Reaktansi Urutan Positif Transformator GI (Ohm)

$\mathrm{X}_{\mathrm{T} 0} \quad=$ Reaktansi Urutan Nol Transformator GI (Ohm)

$\mathrm{Z}_{1 \mathrm{jar}}=$ Impedansi Urutan Positif Jaringan $(\mathrm{Ohm})$

$\mathrm{Z}_{2 \mathrm{jar}}=$ Impedansi Urutan Negatif Jaringan $(\mathrm{Ohm})$

$Z_{0 \text { jar }}=$ Impedansi Urutan Nol Jaringan $(\mathrm{Ohm})$

RN =Resistani Sisi Sekunder Netral Transformator GI

$\mathrm{Z}_{\text {leq }}=$ Impedansi Ekivalen Urutan Positif $(\mathrm{Ohm})$

$\mathrm{Z}_{2 \mathrm{eq}}=$ Impedansi Ekivalen Urutan Negatif (Ohm)

$\mathrm{Z}_{\text {oeq }}=$ Impedansi Ekivalen Urutan Nol (Ohm)

$\mathrm{E}_{\mathrm{ph}}=$ Tegangan Fasa Netral (Volt)

$\mathrm{E}_{\mathrm{ph}-\mathrm{ph}}=$ Tegangan Antar Fasa (Volt)

If $_{3 \text { fasa }}=$ Arus Hubung Singkat Antar 3 Fasa (A)

If $_{2 \text { fasa }}=$ Arus Hubung Singkat Antar 2 Fasa (A)

If $_{1 \text { fasa }}=$ Arus Hubung Singkat 1 Fasa-Tanah (A)

\subsection{Koordinasi Sistem Pengaman Jaringan Distribusi}

Peralatan proteksi perlu dikoordinasikan untuk memastikan bahwa peralatan yang berada di titik terdekat dengan gangguan harus dioperasikan terlebih dahulu.Relay pengaman dengan kemampuan selektif yang baik dibutuhkan untuk mencapai keandalan sistem yang tinggi karena tindakan pengaman yang cepat dan tepat akan dapat mengurangi gangguan menjadi sekecil mungkin[2].

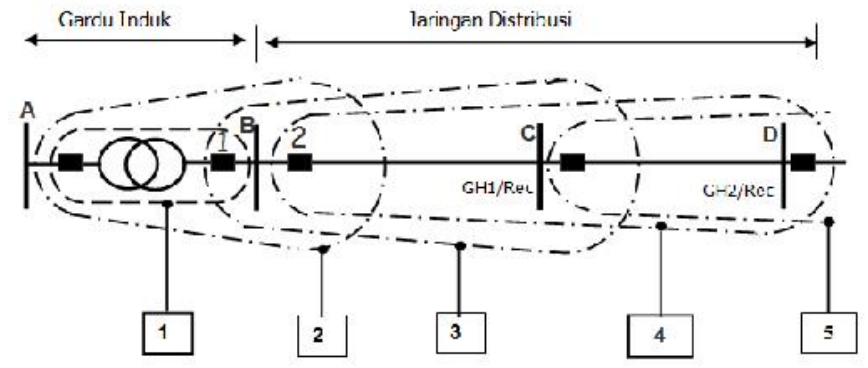

\section{Keterangan :}

1.Differential Relay Pengaman Utama Trafo

2. Over Current Relay Trafo sisi 150 kVPengaman Cadangan LokalTrafoPengaman Cadangan Jauh Bus B

3. OCR dan GFR Trafo sisi $20 \mathrm{kV}$ Pengaman Utama Bus B1 PengamanCadanganJauh saluran BC

4. OCR dan GFR di B2Pengaman Utama saluran BCPengaman Cadangan Jauhsaluran CD

5. OCR dan GFR di C Pengaman Utama saluran CDPengaman Cadangan Jauh seksiberikut

\section{Gambar 1. Sistem PengamanJaringan Distribusi[3]}

Berdasarkan gambar 1, OCR dan GFR trafo sisi $20 \mathrm{kV}$ merupakanpengaman utama busB1 dan sekaligus sebagai pengaman cadanganjauh saluran BC. OCR dan GFR di titik B2 merupakanpengaman utama saluran BC sekaligus sebagai pengaman cadangan Jauhsaluran CD. OCR dan GFR di titik C merupakanpengaman utama saluran $\mathrm{CD}$ sekaligus sebagai pengaman cadangan jauh seksiberikutnya[3].

\subsection{Setting Arus OCR dan GFR}

Pada dasarnya batas settingrelay arus lebih adalah relay tidak boleh bekerja pada saat beban maksimum.Berdasarkan British Standard 142, setting OCR dengan karakteristik inverse time dapat diperoleh dengan menggunakan persamaan[4]:

$$
\left(1,05 \times \mathrm{I}_{\text {beban }}\right) \leq \mathrm{I}_{\text {set low }} \leq\left(1,3 \mathrm{I}_{\text {beban }}\right)
$$

Keterangan:

$\mathrm{I}_{\text {beban }}=$ Arus Beban Jaringan

$\mathrm{I}_{\text {set low }}=$ SettingArus OCR Karakteristik Inverse Time

Pengamanan penyulang dari arus hubung singkat yang besar dapat dilakukan dengan menggunakan relay yang memiliki fungsi dengan karakteristik Instananeous dan definite time. Menurut British Standard 142, batas maksimal settingrelay arus lebih dapat dihitung menggunakan persamaanberikut [4]:

$$
\mathrm{I}_{\text {set-high }} \leq\left(0.8 \times \mathrm{I}_{\mathrm{f} 2 \text { fasa }}\right) \text {. }
$$

Keterangan:

$\mathrm{I}_{\text {set-high }}=$ SettingArus OCR Karakteristik Instantaneous dan Definite Time 
Setting GFR harus disesuaikan dengan sistem pembumian titik netral. Pada sistem dengan pembumian titk netral tranformator GI tahanan rendah (40 ), maka setting arus GFR dapat diperoleh dengan menggunakan persamaan [5]:

$$
\left(10 \% \mathrm{xI}_{\text {set low }}\right) \unlhd_{\text {setGFR }}<\left(100 \% \mathrm{x} \mathrm{I}_{\text {set low }}\right)
$$

Keterangan :

$\mathrm{I}_{\text {set GFR }}=$ Setting Arus GFR

\subsection{Setting Waktu OCR dan GFR}

Setting waktu pada OCR dan GFR dengan karakteristik inverse time menggunakan time multiple setting (TMS), yaitu sebuah persamaan pembentuk kurva arus gangguan terhadap waktu relay bekerja [4].

$$
T M S=\frac{t \times\left[\left[\frac{\text { Ifault }}{\text { Iset }}\right]^{\alpha}-1\right]}{\beta}
$$

Keterangan:

TMS = Time Multiple Setting

Ifault = Arus Hubung Singkat Terbesar (A)

Iset $=$ Setting Arus OCR atau GFR (A)

Tabel 1. Konstanta $\alpha$ dan $\beta$ [4]

\begin{tabular}{|c|c|c|}
\hline Jenis Kurva & $\boldsymbol{\alpha}$ & $\boldsymbol{\beta}$ \\
\hline Standard Inverse (SI) & 0,02 & 0,14 \\
\hline Very Inverse (VI) & 1 & 13,2 \\
\hline Extemly inverse (EI) & 2 & 80 \\
\hline
\end{tabular}

\section{METODE PENELITIAN}

Penelitian ini dilakukan dengan membuat kurva koordinasi proteksi OCR dan GFR menggunakan program ETAP. Datadata yang diperlukan pada penelitian ini adalah data panjang jaringan, impedansi jenis konduktor, reaktansi transformator GI, daya transformator GI, arus hubung singkat sumber, arus nominal penyulang maksimum tahun 2014 dan data setting existing OCR dan GFR tahun 2014.

Proses perhitungan untuk mendapatkan setting yang sesuai dengan syarat-syarat sistem pengaman dimulai dengan menghitung impedansi sumber sisi $150 \mathrm{kV}$, impedansi trafo kapal II, impedansi jaringan distribusi titik 1\% dan titik 100\% panjang jaringan, impedansi ekivalen tiap-tiap zona proteksi pada titik $1 \%$ dan titik $100 \%$ panjang jaringan. Setelah didapatkan nilai impedansi ekivalen, perhitungan dilanjutkan dengan menghitung arus hubung singkat antar 3 fasa, antar 2 fasa dan arus hubung singkat 1 fasa-tanah pada titik $1 \%$ dan $100 \%$ panjang jaringan tiap-tiap zona proteksi. Setting proteksi OCR dan GFR terdiri dari 3 bagian, yang pertama adalah setting arus, setting waktu dan setting karakteristik kurva.Penentuan nilai-nilai setting arus,setting waktu dan setting karakteristik kurva didasarkan pada syarat-syarat sistem pengaman yang sensitif, andal, cepat dan selektif.

\section{METODE PENELITIAN}

\subsection{Impedansi Sumber GI Kapal}

Berdasarkan data dari PT PLN(Persero) P3B RJTB Sub Region Bali, nilai arus hubung singkat $\left(\mathrm{I}_{\mathrm{sc}}\right)$ pada sisi 150 kVsebesar 8,5571 kA. Berdasarkan hasil perhitungan, diperoleh daya hubung singkat sumber sebesar 2.223 MVA dan impedansi sumber $\left(Z_{\mathrm{S} 2}\right)$ pada sisi $20 \mathrm{kV}$ sebesar 0,1799 Ohm.

\subsection{Perhitungan dan AnalisisImpedansi Trafo}

Penyulang Tibubeneng disuplai dari GI Kapal transformator II dengan daya nominal 60 MVA.Tranformator II pada GI Kapal memiliki jenis belitan YNyn0(d1).Impedansi transformator II GI Kapal yang hanya berupa nilai reaktansi yang tertera pada papan spesifikasi transformator dengan nilai sebesar $12.19 \%$. Setelah dilakukan perhitungan, maka diperoleh nilai Impedansi urutan positif transformator sebesar 0,8127 Ohm. Dan impedansi urutan nol sebesar 2,44 Ohm. ..

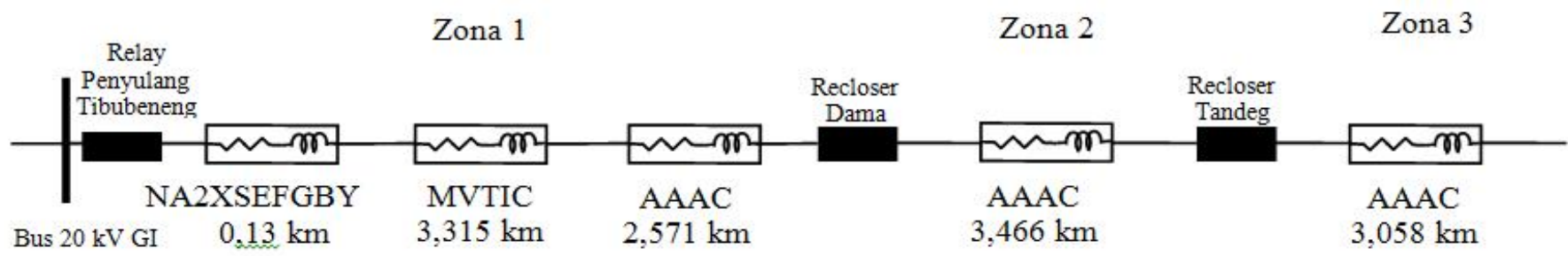

Gambar 2. Impedansi Jaringan Penyulang Tibubeneng 


\subsection{Perhitungan dan Analisis Impedansi Jaringan Distribusi}

Impedansi jaringan distribusi penyulang Tibubeneng dihitung berdasarkan impedansi jenis penghantar dan panjang jaringan SUTM, SKTM dan SKUTM yang terpasang.

Impedansi jaringan pada penyulang Tibubeneng dapat diperoleh dengan cara mengalikan impedansi jenis penghantar dan panjang pada masing-masing penghantar seperti pada data-data sebagai berikut :

1. Kabel tanah NA2XSEFGBY $240 \mathrm{~mm}^{2}$, dengan Impedansi jenis urutan positif $\mathrm{Z}_{1}=0,125+\mathrm{j} 0,097 \Omega / \mathrm{km}$, Impedansi jenis urutan nol $Z_{0}=0,275+\mathrm{j} 0,029 \Omega / \mathrm{km}$ dan panjang kabel $0,13 \mathrm{~km}$

2. Kabel MVTIC $150 \mathrm{~mm}^{2}$, dengan Impedansi jenis urutan positif $Z_{1}=0,206+j 0,014 \Omega / \mathrm{km}$, Impedansi jenis urutan nol $Z_{0}=0,206+\mathrm{j} 0,104 \Omega / \mathrm{km}$ dan panjang kabel 3,315 km

3. Konduktor AAAC $150 \mathrm{~mm}^{2}$, dengan impedansi jenis urutan positif $Z_{1}=0,2162+j 0,3305 \Omega / \mathrm{km}$, Impedansi jenis urutan nol $Z_{0}=0,3631+\mathrm{j} 1,618 \Omega / \mathrm{km}$ dan panjang konduktor pada zona 1 adalah $2,571 \mathrm{~km}$

4. Konduktor AAAC $150 \mathrm{~mm}^{2}$, dengan impedansi jenis urutan positif $\mathrm{Z}_{1}=0,2162+\mathrm{j} 0,3305 \Omega / \mathrm{km}$, Impedansi jenis urutan nol $Z_{0}=0,3631+\mathrm{j} 1,618 \Omega / \mathrm{km}$ dan panjang konduktor pada zona 2 adalah $3,466 \mathrm{~km}$

5. Konduktor AAAC $150 \mathrm{~mm}^{2}$, dengan impedansi jenis urutan positif $\mathrm{Z}_{1}=0,2162+\mathrm{j} 0,3305 \Omega / \mathrm{km}$, Impedansi jenis urutan nol $Z_{0}=0,3631+\mathrm{j} 1,618 \Omega / \mathrm{km}$ dan panjang konduktor pada zona 3 adalah $3,058 \mathrm{~km}$

Berdasarkan data-data impedansi jenis konduktor diatas dan hasil perhitungan, maka diperoleh nilai-nilai impedansi jaringan seperti ditunjukkan pada tabel 2 .

Tabel 2. Impedansi Jaringan

\begin{tabular}{|c|c|c|c|c|c|}
\hline \multirow{2}{*}{$\begin{array}{c}\text { Titik } \\
\text { Jaringan }\end{array}$} & $\begin{array}{c}\text { Impedansi } \\
\text { Jaringan } \\
\text { Urutan Positif }\end{array}$ & \multicolumn{2}{|c|}{$\begin{array}{c}\text { Impedansi } \\
\text { Jaringan Urutan } \\
\text { Nol ( ) }\end{array}$} \\
\cline { 3 - 6 } & $\mathbf{R}$ & $\mathbf{i X}$ & $\mathbf{R}$ & $\mathbf{i X}$ \\
\hline \multirow{2}{*}{$\begin{array}{c}\text { Zona } \\
1\end{array}$} & $1 \%$ & 0,013 & 1,002 & 120,017 & 2,483 \\
\cline { 2 - 6 } & $100 \%$ & 1,255 & 1,901 & 121,652 & 6,946 \\
\hline $\begin{array}{c}\text { Zona } \\
2\end{array}$ & $1 \%$ & 1,262 & 1,913 & 121,665 & 7,002 \\
\cline { 2 - 6 } & $100 \%$ & 2,004 & 3,047 & 122,911 & 12,554 \\
\hline $\begin{array}{c}\text { Zona } \\
3\end{array}$ & $1 \%$ & 2.011 & 3.057 & 122.922 & 12.604 \\
\cline { 2 - 6 } & $100 \%$ & 2,665 & 4,058 & 124,021 & 17,502 \\
\hline
\end{tabular}

\subsection{Perhitungan dan Analisis Impedansi Ekivalen}

Impedansi ekivalen yang akan digunakan dalam analisis ini adalah impedansi ekivalen urutan positif $\left(Z_{\text {leq }}\right)$, Impedansi urutan negatif $\left(\mathrm{Z}_{2 \mathrm{eq}}\right)$ dan impedansi urutan nol $\left(\mathrm{Z}_{0 \mathrm{eq}}\right)$. Masingmasing jenis impedansi ekivalen yang perlu dihitung adalah pada titk $1 \%$ dan $100 \%$ pada tiap-tiap zona proteksi seperti ditunjukkan pada gambar 2 .
Impedansi urutan positif $\left(\mathrm{Z}_{1 \mathrm{eq}}\right)$ dan impedansi urutan negatif $\left(Z_{2 \text { eq }}\right)$ memiliki nilai yang sama akan tetapi berbeda arah arusnya. Berdasarkan hasil perhitungan, diperoleh nilai impedansi ekivalen tiap-tiap zona proteksi pada titik $1 \%$ dan titik $100 \%$ seperti ditunjukkan pada tabel 3 .

Tabel 3. Impedansi Ekivalen

\begin{tabular}{|c|c|c|c|c|c|}
\hline \multirow{2}{*}{\multicolumn{2}{|c|}{$\begin{array}{c}\text { Titik } \\
\text { Jaringan }\end{array}$}} & \multicolumn{2}{|c|}{$\begin{array}{c}\text { Impedansi } \\
\text { Ekivalen } \\
\text { Urutan } \\
\text { Positif ( ) } \\
\end{array}$} & \multicolumn{2}{|c|}{$\begin{array}{c}\text { Impedansi } \\
\text { Ekivalen } \\
\text { Urutan } \\
\text { Nol ( ) } \\
\end{array}$} \\
\hline & & $\mathbf{R}$ & $\mathrm{iX}$ & $\mathbf{R}$ & iX \\
\hline \multirow{2}{*}{$\begin{array}{c}\text { Zona } \\
1\end{array}$} & $1 \%$ & 0,013 & 1,002 & 120,017 & 2,483 \\
\hline & $100 \%$ & 1,255 & 1,901 & 121,652 & 6,946 \\
\hline \multirow{2}{*}{$\begin{array}{c}\text { Zona } \\
2\end{array}$} & $1 \%$ & 1,262 & 1,913 & 121,665 & 7,002 \\
\hline & $100 \%$ & 2,004 & 3,047 & 122,911 & 12,554 \\
\hline \multirow{2}{*}{$\begin{array}{c}\text { Zona } \\
3\end{array}$} & $1 \%$ & 2,011 & 3,057 & 122,922 & 12,604 \\
\hline & $100 \%$ & 2,665 & 4,058 & 124,021 & 17,502 \\
\hline
\end{tabular}

\subsection{Perhitungan dan Analisis Arus Hubung Singkat}

Arus gangguan yang akan dihitung dalam penelitian ini adalah arus hubung singkat antar 3 fasa, antar 2 fasa dan hubung singkat 1 fasa-tanah. Nilai arus hubung singkat yang akan digunakan dalam penelitian ini adalah hanya pada titik $1 \%$ dan $100 \%$ tiap-tiap zona proteksi. Berdasarkan hasil perhitungan, diperoleh nilai arus hubung singkat seperti ditunjukkan pada tabel 4 .

Tabel 4. Arus Hubung Singkat

\begin{tabular}{|c|c|c|c|c|}
\hline \multicolumn{2}{|c|}{ Titik Jaringan } & $\begin{array}{c}\text { If 3fasa } \\
(A)\end{array}$ & $\begin{array}{c}\text { If 2fasa } \\
(A)\end{array}$ & $\begin{array}{c}\text { If 1fasa } \\
(A)\end{array}$ \\
\hline \multirow{2}{*}{ Zona 1 } & $1 \%$ & 11,526 & 9,982 & 288,37 \\
\cline { 2 - 5 } & $100 \%$ & 5,068 & 4,389 & 277,96 \\
\hline \multirow{2}{*}{ Zona 2 } & $1 \%$ & 5,038 & 4,363 & 277,88 \\
\cline { 2 - 5 } & $100 \%$ & 3,166 & 2,742 & 270,04 \\
\hline \multirow{2}{*}{ Zona 3 } & $1 \%$ & 3,155 & 2,732 & 269,97 \\
\cline { 2 - 5 } & $100 \%$ & 2,378 & 2,059 & 262,70 \\
\hline
\end{tabular}

\subsection{Perhitungan Setting OCR dan GFR}

\subsubsection{Perhitungan Setting Arus OCR dan GFR}

Pada dasarnya batas settingrelay arus lebih adalah relay tidak boleh bekerja pada saat beban maksimum. Setting arusnya harus lebih besar dari pada arus beban maksimumnya, maka relay arus lebih yang digunakan harus memiliki fungsi setting arus lebih dengan karakteristik waktu terbalik (inverse time).

Pada setting OCR karakteristik inverse, settingrelay arus lebih pada recloser Tandegadalah 1,3 dikalikan dengan arus beban puncak. Pemilihan faktor kali 1,3 didasari pada kebutuhan saat akan dilakukannya manuver jaringan pada saat operasional sistem.Sedangkan setting arus OCR dengan karakteristik waktu seketika dan definite time pada recloser Tandeg $\leq 0,8$ dikalikan arus hubung singkat antar 2 fasa terkecil.

Setting GFR padarecloser Tandeg ditentukan sebesar $10 \%$ dari setting OCR,recloser Dama ditentukan sebesar 17,5\% dari setting OCR recloser Dama, sedangkan setting GFR pada 
relay penyulang Tibubeneng ditentukan sebesar $13 \%$ dari setting OCR relay penyulang Tibubeneng. Penentuan nilai setting tersebut diatas bertujuan untuk mendapatkan grading time yang cepat dan selektif.Berdasarkan hasil perhitungan, diperoleh nilai setting arus OCR dan GFR seperti ditunjukkan pada tabel 5 .

\subsubsection{Perhitungan Setting waktu OCR dan GFR}

Setting waktu pada OCR dan GFR dengan karakteristik inverse time menggunakan time multiple setting (TMS).Setting TMS pada OCR recloser Tandeg dihitung menggunakan nilai arus gangguan hubung singkat antar 3 fasa terbesar pada zona 3, yaitu pada lokasi panjang jaringan $1 \%$ depan recloser Tandeg. Waktu kerja relay arus lebih pada nilai arus gangguan 3 fasa maksimum ditentukan selama 0,3 detik dengan karakteristik standard inverse. hal ini dimaksudkan untuk menghindari efek arus inrush pada saat pengisian tegangan setelah terjadinya trip ataupun manual load shedding [6].

Penentuan setting TMS pada GFR recloser Tandeg dihitung menggunakan nilai arus hubung singkat 1 fasa-tanah terbesar pada zona 3 dengan karakteristik kurva very inverse.Kurva karakteristik dari setting OCR dan GFR ditentukan berdasarkan kebutuhan grading time dan kecepatan waktu pemutusan relay. Karakteristik kurva OCR dan GFR pada recloser Dama dan relay penyulang Tibubeneng ditentukan menggunakan standard inverse dengan grading time sebesar 0,4 detik. Grading time antar peralatan proteksi sebesar 0,4 detik dimaksudkan untuk meningkatkan seliktifitas sistem pengaman[6].

Setting waktu $\mathrm{OCR}_{\text {high-set }}$ pada recloser Tandeg ditentukan tanpa tunda waktu $(\mathrm{T}=0)$ dan menggunakan karakteristik instantaneous. Penentuan karakteristik instantaneous $(\mathrm{T}=0)$ pada OCR $_{\text {high-set }}$ didasari pada letak recloser Tandeg sebagai pengaman jaringan zona terakhir yang memerlukan pemutusan seketika pada saat terjadi arus gangguan hubung singkat yang relatif besar.Tunda waktupada recloser Dama sebesar 0,4 detik $(\mathrm{T}=0,4)$ lebih lambat dari tunda waktu recloser Tandeg, sedangkan pada relay penyulang Tibubeneng lebih lambat 0,4 detik dari pada recloser Dama $(\mathrm{T}=0,8)$ dengan karakteristik definite time.Berdasarkan hasil perhitungan,diperoleh setting waktu seperti ditunjukkan pada tabel 5.

Tabel 5. Setting OCR dan GFR Hasil Perhitungan

\begin{tabular}{|c|c|c|c|c|}
\hline \multicolumn{2}{|c|}{ Setting } & $\begin{array}{c}\text { Relay } \\
\text { Penyulan }\end{array}$ & $\begin{array}{c}\text { Recloser } \\
\text { Dama }\end{array}$ & $\begin{array}{l}\text { Recloser } \\
\text { Tandeg }\end{array}$ \\
\hline \multirow{3}{*}{$\begin{array}{c}\text { OCR } \\
\text { low- } \\
\text { set }\end{array}$} & I Set (A) & 252 & 174 & 131 \\
\hline & TMS & 0,62 & 0,35 & 0,14 \\
\hline & Kurva & SI & SI & SI \\
\hline \multirow{3}{*}{$\begin{array}{c}\text { OCR } \\
\text { Hi- } \\
\text { Set } \\
\end{array}$} & I Set (A) & 3511 & 2193 & 1648 \\
\hline & T (Sec) & 0,8 & 0,4 & 0 \\
\hline & Kurva & Definite & Definite & Instantaneo \\
\hline \multirow{3}{*}{ GFR } & I Set (A) & 32,79 & 30,49 & 13,1 \\
\hline & TMS & 0,35 & 0,23 & 0,44 \\
\hline & Kurva & SI & SI & VI \\
\hline
\end{tabular}

\subsection{Analisis kurva koordinasi proteksi OCR dan GFR}

4.7.1 Analisis kurva koordinasi proteksi OCR dan GFRsetting existing

Berdasarkan data dari PT PLN (Persero) Distribusi Bali, data setting kondisi existing OCR dan GFR relay penyulang Tibubeneng, recloser Dama dan recloser Tandeg ditunjukkan pada tabel 6 .

Tabel 6. Setting OCR dan GFR kondisi existing

\begin{tabular}{|c|c|c|c|c|}
\hline \multicolumn{2}{|c|}{ Setting } & $\begin{array}{c}\text { Relay } \\
\text { Penyulang } \\
\text { Tibubeneng }\end{array}$ & $\begin{array}{c}\text { Recloser } \\
\text { Dama }\end{array}$ & $\begin{array}{c}\text { Recloser } \\
\text { Tandeg }\end{array}$ \\
\hline \multirow{3}{*}{$\begin{array}{l}\text { OCR } \\
\text { low- } \\
\text { set }\end{array}$} & I Set (A) & 304 & 250 & 200 \\
\hline & TMS & 0,18 & 0,125 & 0,1 \\
\hline & Kurva & SI & SI & VI \\
\hline \multirow{3}{*}{$\begin{array}{c}\text { OCR } \\
\text { Hi- } \\
\text { Set }\end{array}$} & I Set (A) & 4080 & 3080 & 2000 \\
\hline & T (Sec) & 0,3 & 0,1 & 0 \\
\hline & Kurva & Definite & Definite & Instantaneous \\
\hline \multirow{3}{*}{ GFR } & I Set (A) & 40 & 34 & 30 \\
\hline & TMS & 0,25 & 0,11 & 0,1 \\
\hline & Kurva & SI & SI & VI \\
\hline
\end{tabular}

Berdasarkan Kurva koordinasi OCR dan GFR setting existing pada gambar 3 dan gambar 4, selektifitas sistem pengaman hubung singkat pada penyulang Tibubeneng masih kurang baik. Grading time pada beberapa nilai arus hubung singkat yang masih berada dibawah 0,2 detik menunjukkan kurangnya tingkat selektifitas sistem pengaman.

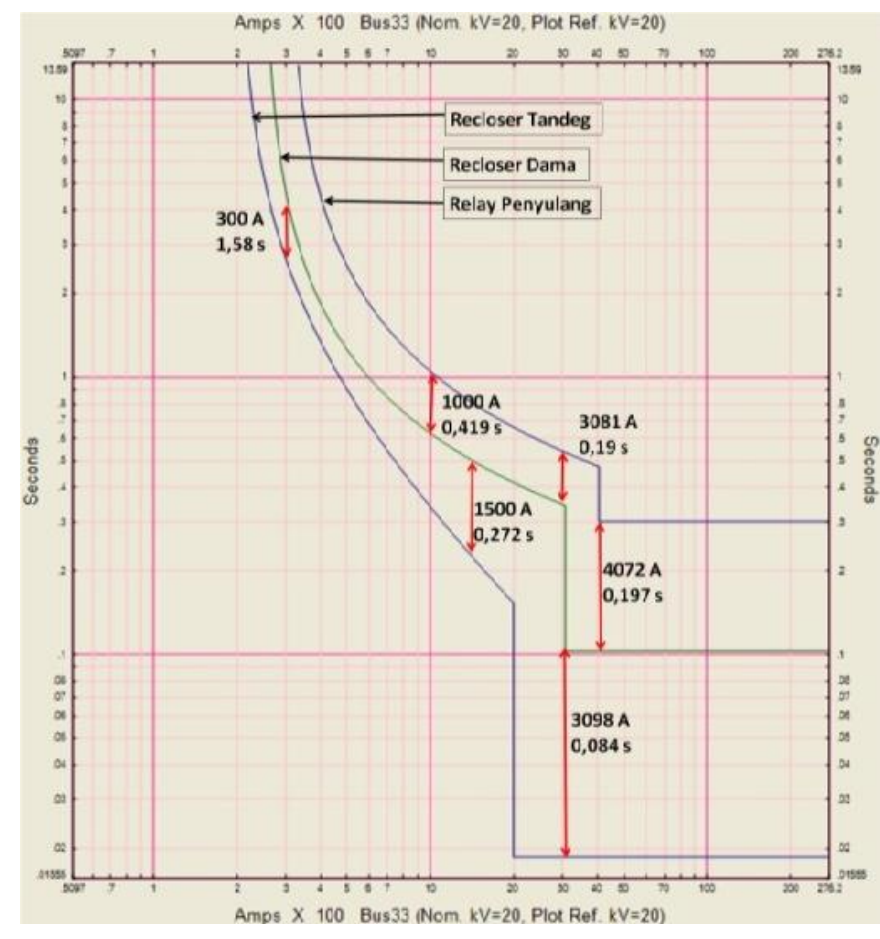

Gambar 3. Kurva koordinasi OCRsetting Existing 


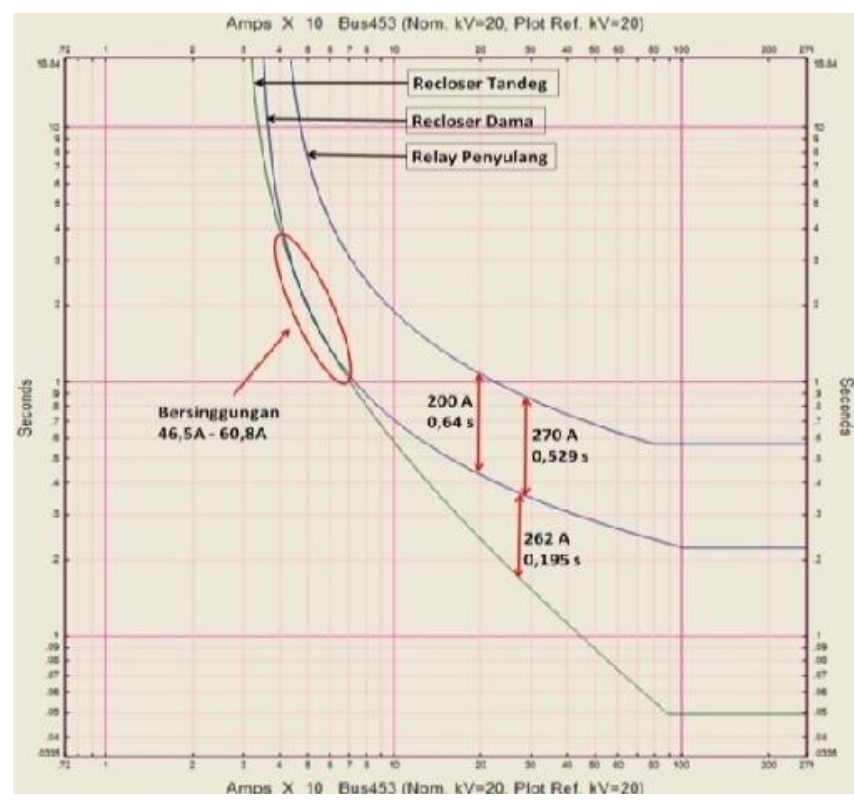

Gambar 4. Kurva koordinasi GFR settingexisting

Kesalahan koordinasi setting GFR juga ditunjukkan oleh adanya perpotongan kurva antara recloser Tandeg dan recloser Dama pada nilai arus hubung singkat 46,5 A sampai dengan 60,8 A. Koordinasi sistem pengaman yang kurang baik dan tidak memenuhi syarat akan menimbulkan terjadinya overlap antar peralatan proteksi atau bekerjanya dua peralatan proteksi secara bersamaan.

\subsubsection{Analisis kurva koordinasi proteksi OCR dan GFRsetting Hasil Perhitungan}

Berdasarkan kurva koordinasi OCR dan GFR setting hasil perhitungan pada gambar 5 dan gambar 6 , selektifitas sistem pengaman hubung singkat sudah memenuhi syarat sistem pengaman yang baik.Grading time antar peralatan pengaman pada semua tingkatan arus hubung singkat menunjukkan nilai lebih dari 0,4 detik.

Grading time yang berada pada nilai 0,4 detik atau lebih akan memberikan kesempatan relay untuk memerintahkan circuit breaker (CB) bekerja, sehingga tidak menyebabkan peralatan pengaman di sisi hulunya bekerja terlebih dahulu (overlap) atau bekerja secara bersamaan. Koordinasi sistem pengaman yang memenuhi syarat selektif, cepat, andal dan selektif akan meminimalisir luasnya daerah padam yang disebabkan oleh gangguan hubung singkat yang terjadi pada jaringan.

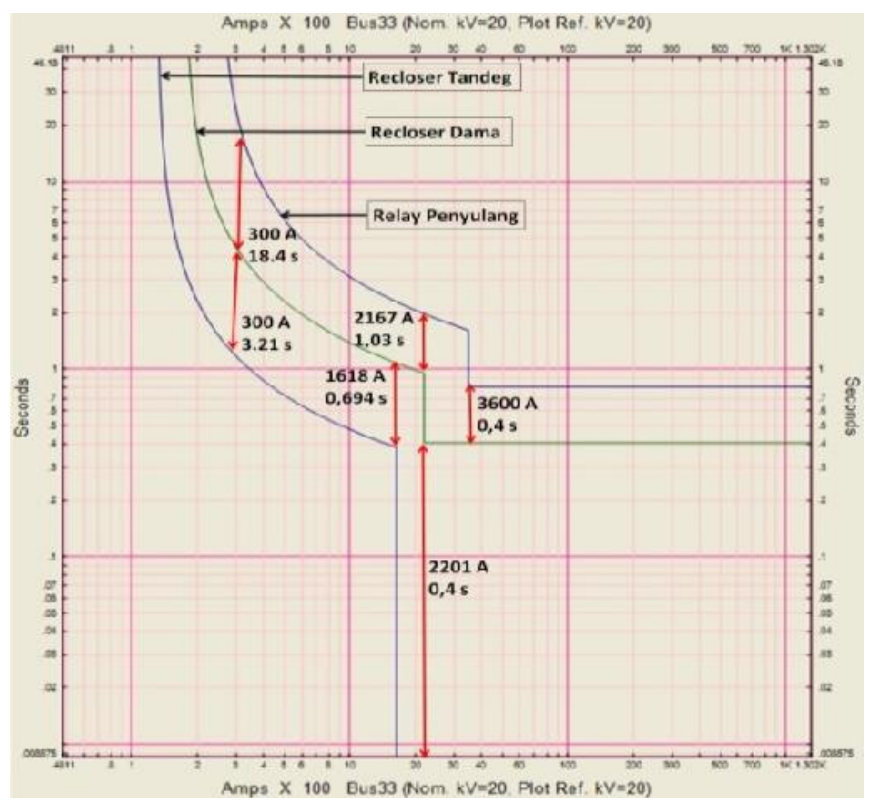

Gambar 5. Kurva koordinasi OCRsetting Hasil Perhitungan

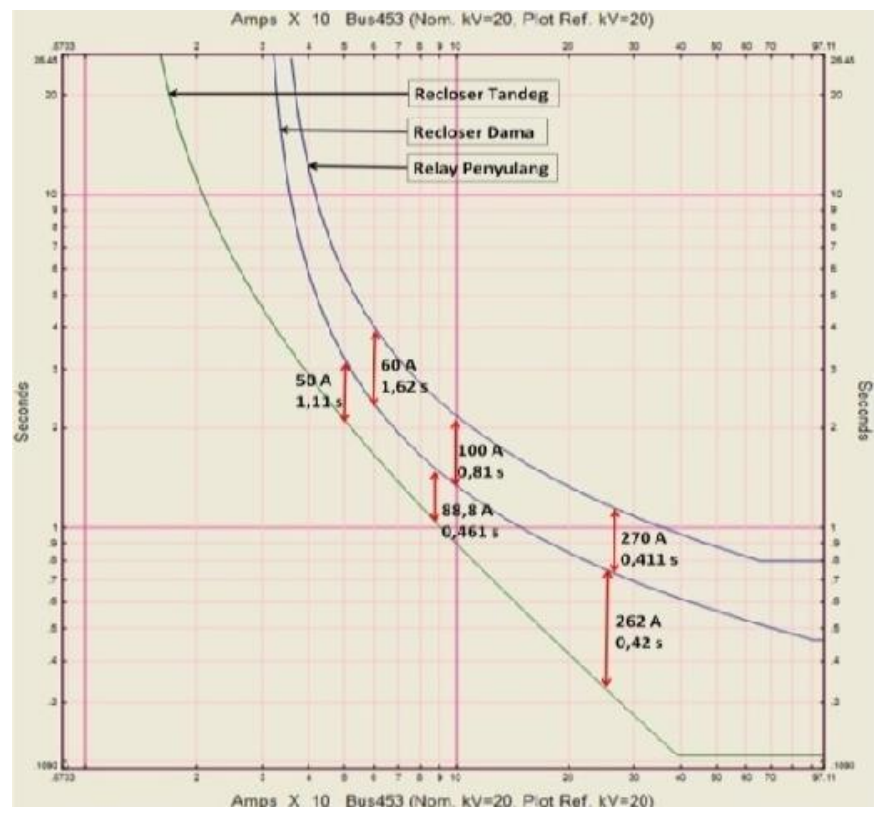

Gambar 6. Kurva koordinasi GFR setting Hasil Perhitungan

\section{KESIMPULAN}

1. Koordinasi seting Over Current Relay ( OCR) dan Ground Fault Relay (GFR) pada relay penyulang Tibubeneng, recloser Dama dan recloser Tandeg masih kurang baik. Grading time antara ketiga peralatan proteksi hubung singkat pada beberapa nilai arus hubung singkat masih dibawah 0,2 detik dan adanya perpotongan garis kurva menyebabkan kemungkinan ketiga peralatan tersebut mengalami trip secara bersamaan atau saling overlap. 
2. Penentuan nilai setting arus, setting waktu dan pemilihan karakteristik kurva sangat mempengaruhi tingkat koordinasi sistem proteksi.

3. Setting OCR dan GFR relay penyulang Tibubeneng, recloser Dama dan recloser Tandeg direkomendasikan untuk dilakukan setting ulang sesuai dengan hasil perhitungan.

\section{DAFTAR PUSTAKA}

[1] Grainger, J.J.,Stevenson, Jr.W.D. Analisa Sistem Tenaga terjemahan Ir.Kamal Idris, cetakan keempat,Jakarta : Erlangga. 1994.

[2] Wellinton.Art of Protective Relaying terjemahan Ir. Pribadi Kadarisman. Jakarta; Udiklat Teknologi Kelistrikan. 1971.

[3] Kadarisman,P., Sarimun,W.N. Proteksi Sistem Distribusi Tegangan Menengah, Jakarta: PT.PLN (Persero). 2009.

[4] British Standard. 142.Electrical protection relay. Requirements for the families of protection relays.Spesification for thermal electrical relays.London :British Standard Institution. 1991.

[5] IEEE Standards Association. 242.Recommended Practice for Protection and Coordination of Industrial and Commercial Power Systems. New York: The Institute of Electrical and Electronics Engineers, Inc. 2001.

[6] Blackburn,J.L.,Domin,T.J. Protective Relaying Principle and Application.Third Edition London: Taylor \& Francis Group. 2006 